\title{
THE CORRELATION BETWEEN THE DURATION OF FETAL EXTRACTION DURING ELECTIVE CESAREAN SECTION AND DEVELOPMENT OF TRANSIENT TACHYPNEA OF THE NEWBORN
}

By

\section{Ahmed Farouk Zaki Mousa, Abd Al-Monsef Abd El-Hamed Sedek and Ismael Mohamed Abd El-Azim Mira}

Department of Obstetrics and Gynecology, Faculty of Medicine, Al-Azhar University

Corresponding author: Ahmed Farouk Zaki Mousa, Mobile: (+20) 01024560009,

E-mail: drahmedfarouk8722@gmail.com

\begin{abstract}
Background: A cesarean section (C.S) is usually performed when a vaginal delivery would put the baby's or mother's life or health at risk. Delivery by cesarean section is one of the major risk factors for transient tachypnea of the new born (TTN).

Objective: The current study was designed to assess the relation between the duration of fetal extraction during cesarean section and Apgar score.

Patients and methods: Fifty pregnant women were included in the study fulfilling the inclusion and exclusion criteria. Time from incision of skin till clamping of the cord and time from incision of the uterus till clamping of the cord were recorded. Apgar score at 1 and at 5minutes, respiratory rate and weight of neonate were reported and the occurrence of TTN among the studied neonates.

Results: No correlation between the duration of fetal extraction and Apgar score recorded at 5 minutes. It was noticed that absence of significant correlation between TTN development and history of previous cesarean section, there is no significant relation between BMI and development of TTN. It was noticed that absence of significant correlation between the time from incision of skin till clamping of the cord (S-C interval) and the development of TTN Also there is no statically significant correlation between development of TTN and between the time from incision of uterus till clamping of the cord (U-C interval).

Conclusion: No correlation between the duration of fetal extraction during cesarean section and development of transient tachypnea of the newborn.
\end{abstract}

Keywords: Duration of fetal extraction, cesarean section, TTN, Apgar score.

\section{INTRODUCTION}

Cesarean delivery is associated with increased risks for adverse obstetric and perinatal outcomes in the subsequent birth as malpresentation, placenta previa, antepartum hemorrhage, placenta accreta, prolonged labor, uterine rupture, preterm birth, low birth weight, and stillbirth in their second delivery (Kilicci et al., 2017).

Cesarean sections performed without antecedent labor are associated with a higher risk of respiratory distress than those performed after the onset of labor, despite the fact that they may have been 
done at full term (at least 37 weeks of gestation) (Raju et al., 2014).

As compared with infants born vaginally, those born by cesarean section are at increased risk for adverse respiratory outcomes, especially when delivery occurs before the onset of labor (Spong et al., 2011).

Cesarean delivery at term was associated with a higher neonatal morbidity, NICU admission and maternal pain in the puerperium. It also reduces exclusive breastfeeding rate at discharge (Cernadas et al., 2010).

Neonates born via elective cesarean section have a higher risk of respiratory complications such as respiratory distress syndrome or transitory tachypnea of the newborn (Wilminket al., 2010 and Prefumo et al., 2016).

Transient tachypnea of the newborn (TTN) is also called wet lung, and it is one of the most common causes of perinatal dyspnea. The incidence rates of TTN are $4.0 \%$ to $5.7 \%$ among term infants and $10.0 \%$ among premature infants (Liu et al., 2014).

The Apgar score was devised in 1952 by Dr. Virginia Apgar as a simple and repeatable method to quickly and summarily assess the health of newborn children immediately after birth (Obsa et al., 2020).A severely low Apgar score at 5 minutes is strongly associated with an increased risk of neonatal encephalopathy, subsequent cerebral palsy (CP) and learning difficulties (Lie et al., 2010).

Each of five easily identifiable characteristics - heart rate, respiratory effort, muscle tone, reflex irritability, and color - is assessed and assigned a value of 0 to 2. The total score is the sum of the five components and a score of 7 or higher indicates that the baby's condition is good to excellent. The Apgar score is determined at one and five minutes after delivery and is therefore a rapid way to evaluate the physical condition of newborn infants. Of the two scores, the five-minute score has come to be regarded as the better predictor of survival in infancy (Li et al., 2013).

This study was designed to assess the relation between the duration of fetal extraction during cesarean section and the incidence or occurrence of transient tachypnea of the newborn.

\section{PATIENTS AND METHODS}

The present study was carried out in Obstetrics and Gynecology department, in El Sayed Galal hospital and Al-Hussein Hospital Al-Azhar University.

Pregnant women eligible for the study had the following inclusion criteria: Elective cesarean section, primary and repeat cesarean section, no history of medical disorders, and gestational age between 38 weeks to 40 weeks (calculated by the first day of last menstrual period).

Pregnant women who had any of the following conditions were excluded from the study: Cesarean section due to fetal distress, fetal congenital anomalies, multiple pregnancies, intra uterine growth retardation (IUGR), general anesthesia, maternal drug intake before C.S which may affect the neonatal wellbeing e.g. "narcotics", antepartum hemorrhage, maternal medical disorders, e.g diabetes mellitus (DM), hypertension, 
antiphospholpid syndrome, and premature rupture of membrane.

Fifty pregnant women were included in the study fulfilling the inclusion and exclusion criteria.

Patients included in the study were subjected to the following:

1. Informed written consent,

2. Full history takin,

3. Thorough clinical examination,

4. Laboratory investigations,

5. Ultrasound to asses biophysical profile (BPP), which included amniotic fluid index (AFI), fetal movement, fetal tone, fetal breathing, and non-stress test using cardiotocography (CTG), to assess fetal wellbeing, and to confirm the gestational Age.

Neonatal assessment: Follow up the neonate for Apgar score at $1 \mathrm{~min}$ and 5 min, in addition to assess the neonatal weight.

Time from incision of the skin till clamping of the cord and time from incision of the uterus till clamping of the cord were recorded. Apgar score at 5 minutes, respiratory rate and weight of neonate were reported. Occurrence of transient tachypnea of newborn (TTN) among the studied neonates was observed.
Primary outcome variable was to assess the relation between the development of TTN and the following variables:

1. The duration of fetal extraction starting from incision of the skin till clamping of the cord.

2. The duration of fetal extraction starting from the incision of the uterus, till clamping of the cord.

The secondary outcome variables were to assess the relation between the development of TTN and multiple cesarean section and gestational age.

\section{Statistical analysis:}

The data were collected, coded, revised, verified, and computerized. Statistical analyses were done using SPSS statistical package version 21. (IBM Corp, Chicago, IL, USA) Qualitative data were presented in the form of numbers and percentages and quantitative variables as mean and standard deviation (SD). A comparison between quantitative variables was carried out by the student's t-test of two independent samples. Chi-square test (X2) was used to compare qualitative variables. Correlations were calculated using Pearson's correlation. $\mathrm{P}$ value $<0.05$ was considered significant. 


\section{RESULTS}

In the current study the gestational age of the selected cases ranged between 38 and 40 wks. with mean $(38.93 \pm 0.76)$.In this study the maternal age was ranged from 18 to 40 years with mean (28.64 \pm 5.53$)$. 12 women had their $1 \mathrm{st}$ cesarean section during this study, while the other 38 went through different numbers of cesarean section before going through the study, percentage of pregnant women who underwent cesarean section for the $1^{\text {st }}$ time, and those with different number of cesarean sections. Different fetus Presentation was observed in this study of which 45 were cephalic, with 4 breech and 1 transverse lie (Table 1).

\section{Table (1): Baseline characteristics of the women group}

\begin{tabular}{|l|c|}
\hline \multicolumn{1}{|c|}{ Parameters } & Total (n=50) \\
\hline Gestational age (wks) & $22(44.0 \%)$ \\
38 wks. & $19(38.0 \%)$ \\
39 wks. & $9(18.0 \%)$ \\
40 wks. & $38-40$ \\
Range & $38.93 \pm 0.76$ \\
Mean \pm SD & \\
\hline Maternal age (years) & $18-40$ \\
Range & $28.64 \pm 5.53$ \\
Mean \pm SD & \\
\hline Gravidity & $18(36.0 \%)$ \\
Primigravida & $12(24.0 \%)$ \\
Previous 1 CS & $20(40.0 \%)$ \\
Previous 2/more CS & \\
\hline Different fetus presentation & $45(90.0 \%)$ \\
Cephalic & $4(8.0 \%)$ \\
Breech & $1(2.0 \%)$ \\
Transverse & \\
\hline
\end{tabular}

Apgar score after 1 min and 5 minute in correlation with the different variables of the study shows no correlation with the duration from incision of the skin till clamping of the cord, and the duration from incision of the uterus till clamping of the cord. Also there was no correlation between Apgar score at $1 \mathrm{~min}$ and 5 minute and both BMI of the pregnant women, neonatal weight and the gestational age (Table 2).

Table (2): Correlation between Apgar 1 min and 5 minutes with other parameters

\begin{tabular}{|l|c|c|c|c|}
\hline \multirow{2}{*}{ Parameters } & \multicolumn{2}{c|}{ Apgar score 1 min } & \multicolumn{2}{c|}{ Apgar score 5 min. } \\
\cline { 2 - 5 } & Correlation & P value & Correlation & P value \\
\hline Ptn age & 0.126 & 0.603 & 0.224 & 0.216 \\
\hline GA & 0.010 & 0.837 & 0.359 & 0.374 \\
\hline BMI & 0.029 & 0.986 & 0.013 & 0.938 \\
\hline Neonatal Weight & 0.222 & 0.220 & 0.253 & 0.101 \\
\hline SC interval & 0.136 & 0.562 & 0.197 & 0.320 \\
\hline UC interval & 0.262 & 0.078 & 0.264 & 0.091 \\
\hline
\end{tabular}


There was statistically significant decrease in mean of TTN compared to No TTN according to GA; however neonatal weight, maternal BMI, gravidity or neonatal gender were insignificant (Table 3).

Table (3): Comparison between TTN and No TTN according to all parameters of the study group

\begin{tabular}{|l|c|c|c|c|}
\hline \multicolumn{1}{|c|}{ Parameters } & $\begin{array}{c}\text { TTN } \\
(\mathbf{n = 4})\end{array}$ & $\begin{array}{c}\text { No TTN } \\
(\mathbf{n}=\mathbf{4 6})\end{array}$ & $\mathbf{t} / \mathbf{x}$ 2\# & p-value \\
\hline GA (wks) & $38.34 \pm 7.28$ & $38.84 \pm 7.38$ & 7.944 & $\mathbf{0 . 0 0 7 *}$ \\
\hline Neonatal weight (gm) & $3153.15 \pm 283.78$ & $3353.35 \pm 301.80$ & 4.946 & 0.382 \\
\hline Maternal BMI & $28.33 \pm 2.55$ & $28.53 \pm 2.57$ & 1.613 & 0.798 \\
\hline Gravidity & $1(25.0 \%)$ & $17(37.0 \%)$ & & \\
Primigravida & $2(50.0 \%)$ & $10(21.7 \%)$ & $6.918 \#$ & 0.135 \\
Previous 1 CS & $1(25.0 \%)$ & $19(41.3 \%)$ & & \\
Previous 2/more CS & $6.43 \pm 1.22$ & $8.67 \pm 1.65$ & 4.707 & 0.412 \\
\hline Apgar score 5min. & $3.57 \pm 0.32$ & $3.15 \pm 0.21$ & 3.565 & 0.554 \\
\hline U-C & $14.09 \pm 1.27$ & $12.95 \pm 1.17$ & 7.216 & 0.098 \\
\hline S-C & $2(50 \%)$ & $21(45.7 \%)$ & & \\
\hline Neonatal gender & $2(50 \%)$ & $25(54.3 \%)$ & $4.540 \#$ & 0.433 \\
Male & & & \\
Female & &
\end{tabular}

\section{DISCUSSION}

This study included 50 women, and as regarding the results, the gestational age was statistically significant with transient tachypnea of newborn (TTN), as gestational age increased the incidence of TTN decreases.

The present study agreed with a study done by Badran and Colleagues (2012) shows that $\mathrm{GA}<38$ weeks was found to be associated with increased risk for TTN in infants delivered by elective CS. TTN was associated with significant morbidities and longer hospital stay. Delivery by CS and younger GA are risk factors for TTN. Although TTN is a self-limited disease, it is associated with significant morbidities. Scheduling elective C.S at G.A of not less than 38 weeks may decrease the frequency of TTN (Tutdibi et al., 2010).

The study done by Tita and co-workers indicates that for elective cesarean delivery, fewer problems occur if the surgery is delayed until fetal gestational age is older than 39 weeks and younger than41 weeks. Complications, particularly those related to the newborn respiratory system, were more frequent if elective cesarean delivery was performed in the 37 th through 38 th week of gestation i.e. elective repeat cesarean delivery before 39 weeks of gestation is common and is associated with respiratory and other adverse neonatal outcomes (Prefumo et al., 2016).

Robinson et al., (2010) suggested that there are benefits to waiting until 39 weeks of gestation to perform an elective repeat cesarean delivery. The model demonstrated increased costs through increasing adverse outcomes among elective repeat cesarean deliveries performed <39 weeks of gestation. 
There was no statistically significant correlation between U-C interval and Apgar score recorded after 5 minutes.

The present study agreed with a study done by Maayan-Metzger and Colleagues (2010) showed no significant correlations between most of the major neonatal shortterm clinical outcomes and duration of the 3 major stages of elective cesarean delivery at term (from induction of regional anesthesia to delivery (I-D); from incision of the skin to delivery $(\mathrm{S}-$ $\mathrm{D})$; and from incision of the uterus to delivery (U-D)). The results indicate that obstetricians performing elective cesareans for term pregnancies under regional anesthesia have a relatively large timeframe in which to perform the operation without affecting neonatal wellbeing.

The present study agreed with a study done by Omar and Colleagues (2012) and showed no correlation between the duration of fetal extraction (either initiation of anesthesia till cord clamping interval up to uterine incision till cord clamping interval up to 4.5 minutes) and Apgar score recorded at 1 minute and 5 minutes.

It was noticed, in the present study, the absence of significant correlation between the S-C or U-C interval and the occurrence of TTN. ZAHER et al., (2018) showed that the duration of fetal extraction from initiation of anesthesia until extraction of fetus during cesarean section has no effect on incidence of transient tachypnea of the newborn. While, the increase in duration of fetal extraction during cesarean section is associated with increase in neonatal respiratory rate.
The current results showed no significant correlation between multiple cesarean section and development of TTN. In the current study there was no statistically significant correlation between neonatal gender and TTN, with .The present study agreed with a study done by Derbent and co-workers (2011) who showed that low gestational age, C.S delivery, and male sex are independent risk factors for TTN.

In the present study, there was no significant correlation between the BMI of the pregnant women and neonatal outcome, assessed by Apgar score recorded after $1 \mathrm{~min}$ and $5 \mathrm{~min}$. Against the present study Straube et al., (2010), demonstrated an influence of maternal BMI on Apgar scores. Also, Chen et al., (2010) concluded that maternal obesity is associated with a significantly increased risk for decreased Apgar scores at birth.

\section{CONCLUSION}

- Gestational Age is risk factors for the development of TTN; cesarean section is preferred to be done at 39 weeks.

- No correlation between the duration of fetal extraction, either S-C interval up to 22 minutes or U-C interval up to 4 minutes and development of TTN.

- No correlation between the duration of fetal extraction, either S-C interval U-C interval, and Apgar score, recorded at 5 minutes.

- Apgar score is an effective simple procedure to assess the neonatal outcome.

\section{CONFLICT OF INTEREST}

The authors declare no conflict of interest. 


\section{REFERENCES}

1. Badran, E. F., Abdalgani, M. M., AlLawama, M. A., Al-Ammouri, I. A., Basha, A. S., Al Kazaleh, F. A., ... and Khader, Y. S. (2012): Effects of perinatal risk factors on common neonatal respiratory morbidities beyond 36 weeks of gestation. Saudi Med J, 33(12): 1317-23.

2. Cernadas JM, Mariani G and Pardo A, (2010): Cesarean delivery at term in low risk pregnancies: effects on neonatal morbidity. Arch Argent Pediatric, 108(1):17-23.

3. Chen M, McNiff $C$ and Madan (2010): Maternal obesity and neonatal Apgar scores. J Matern Fetal Neonatal Med., 23(1):89-95.

4. Derbent A, Tatli MM and Duran M, (2011): Transient tachypnea of the newborn: effects of labor and delivery type in term and preterm pregnancies. Arch Gynecol Obstet., 283(5):947-51.

5. Kilicci, Ç., Eken, M. K., Ilhan, G., Çogendez, E., Şanverdi, İ., Keskin, M., ... and Karateke, A. (2017): Evaluation of Risk Factors, Incidence, Perinatal and Maternal Outcome of Placenta Previa Cases with and without Placenta Accreta Spectrum. Düzce T1p Fakültesi Dergisi, 19(3), 75-80.

6. Li, F., Wu, T., Lei, X., Zhang, H., Mao, M., and Zhang, J. (2013): The Apgar score and infant mortality. PloS one, 8(7):18-24

7. Lie, K. K., Grøholt, E. K., and Eskild, A. (2010): Association of cerebral palsy with Apgar score in low and normal birth weight infants: population based cohort study. BMJ, 341, c4990-5000.

8. Liu, J., Wang, Y., Fu, W., Yang, C. S., and Huang, J. J. (2014): Diagnosis of neonatal transient tachypnea and its differentiation from respiratory distress syndrome using lung ultrasound. Medicine, 93(27):130-138.

9. Maayan-Metzger A, Schushan-Eisen I, Todris L, (2010): The effect of time intervals on neonatal outcome in elective cesarean delivery at term under regional anesthesia. Int J Gynaecol Obstet., 111(3):224-8.

10. Obsa, M. S., Shanka, G. M., Menchamo, M. W., Fite, R. O., and Awol, M. A. (2020):
Factors Associated with Apgar Score among Newborns Delivered by Cesarean Sections at Gandhi Memorial Hospital Addis Ababa. Journal of Pregnancy, 70(18)45-50.

11. Omar AM, Mohamed HA and Mahmoud MA. (2012): The correlation between the duration of fetal extraction during elective cesarean section and low Apgar score.Med J Cairo Univ., 80(1): 175-180.

12. Prefumo, F., Ferrazzi, E., Di Tommaso, M., Severi, F. M., Locatelli, A., Chirico, G. and Frusca, T. (2016): Neonatal morbidity after cesarean section before labor at $34+0$ to $38+6$ weeks: a cohort study. The Journal of Maternal-Fetal \& Neonatal Medicine, 29(8): 1334-1338.

13. Raju, T. N., Mercer, B. M., Burchfield, D. J., and Joseph Jr, G. F.(2014): Perivale birth: executive summary of a joint workshop by the Eunice Kennedy Shriver National Institute of Child Health and Human Development, Society for Maternal-Fetal Medicine, American Academy of Pediatrics, and American College of Obstetricians and Gynecologists. American journal of obstetrics and gynecology, 210 (5): 406-417.

14. Robinson CJ, Villers MS and Johnson DD, (2010): Timing of elective repeat cesarean delivery at term and neonatal outcomes: a cost analysis. Am J Obstet Gynecol., 202(6):632-6.

15. Robinson, C. J., Villers, M. S., Johnson, D. D., and Simpson, K. N. (2010): Timing of elective repeat cesarean delivery at term and neonatal outcomes: a cost analysis. American journal of obstetrics and gynecology, 202(6), 632-e1.

16. Spong, C. Y., Mercer, B. M., D'Alton, M., Kilpatrick, S., Blackwell, S., and Saade, G. (2011): Timing of indicated late-preterm and early-term birth. Obstetrics and gynecology, 118(2 Pt 1), 323-330.

17. Straube S, Voigt M, Jorch G, (2010): Investigation of the association of Apgar score with maternal socio-economic and biological factors: an analysis of German perinatal statistics. Arch Gynecol Obstet., 282(2):135-41. 
18. Tutdibi, E., Gries, K., Bücheler, M., Misselwitz, B., Schlosser, R. L., and Gortner, L. (2010): Impact of labor on outcomes in transient tachypnea of the newborn: population-based study. Pediatrics, 125(3): e577-e583.

19. Wilmink, F. A., Hukkelhoven, C. W., Lunshof, S., Mol, B. W. J., van der Post, J. A. and Papatsonis, D. N. (2010): Neonatal outcome following elective cesarean section beyond 37 weeks of gestation: a 7-year retrospective analysis of a national registry. American Journal of Obstetrics and Gynecology, 202(3): 250-e1.

20. ZAHER, D. S. A., MOHAMAD, M. E. B., KHALIL, M. M. S., and ABD EL, A. E. R. A. (2018): The Correlation between the Duration of Fetal Extraction during Cesarean Section and Development of Transient Tachypnea of the Newborn. The Medical Journal of Cairo University, 86(March), 611615. 


\section{العلاقة بين الوقت المستغرق في خروج الجنين أثناء الولادة

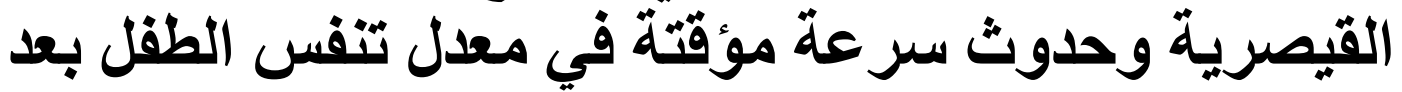

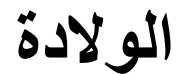

أحمد فاروق زكي، عبد المنصف عبد الحميد صديق، إسماعيل عبد العظيم ميرة قسم النساء والتوليد، كلية|لطب، جامعة/الأزهر

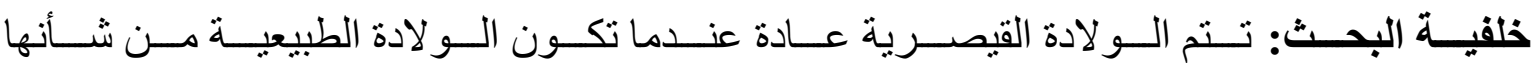

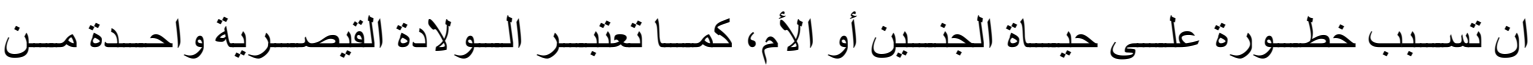
العو امل الكبيرة التي قد تسبب سر عة مؤقته في تنفس المولود.

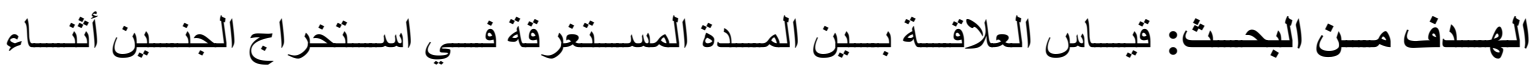
أجر اء الو لادة القيصرية وحدوث سر عة مؤقتة في معدل تتفس المولود.

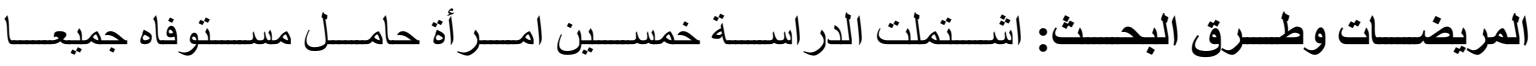

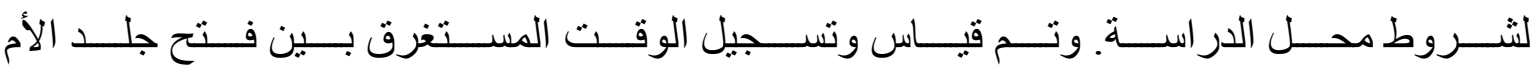

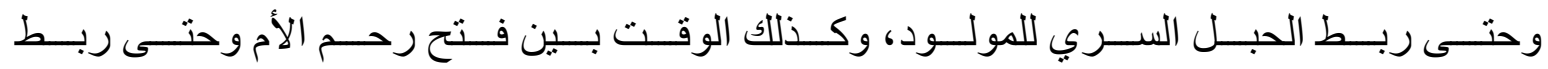

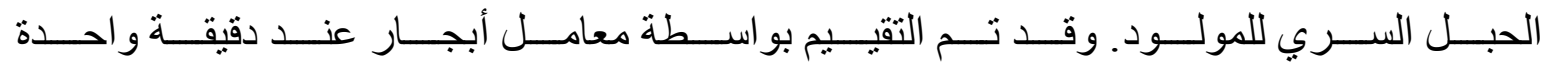

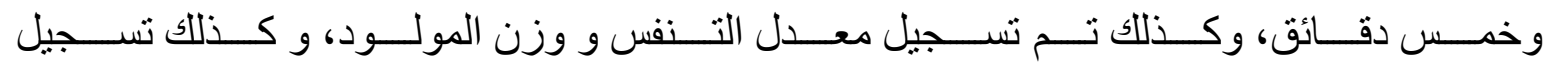
معدل حدوث السر عة المؤقتة في تنفس المولود.

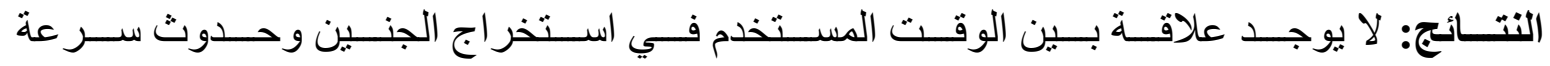

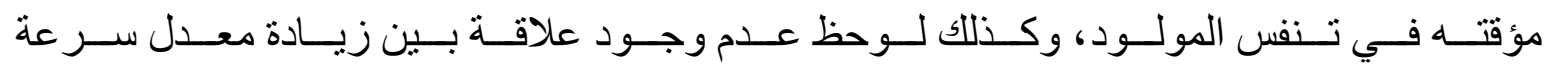

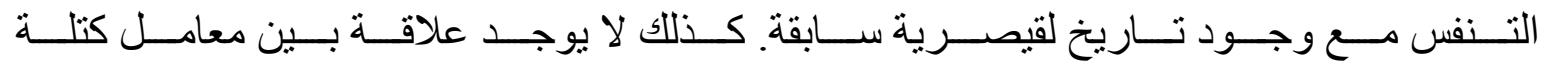

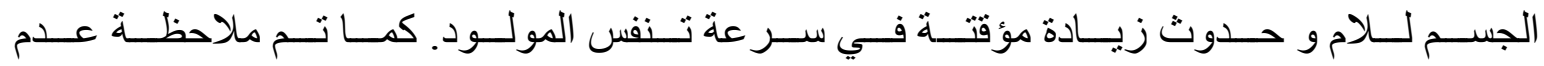

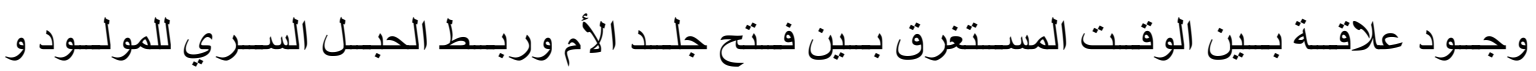

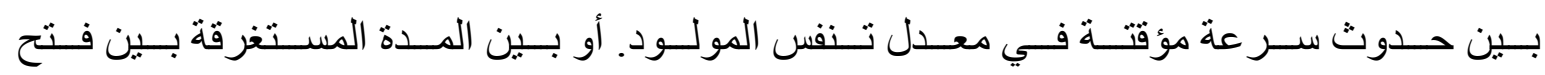
رحم الأم و ربط الحبل السري للمولود.

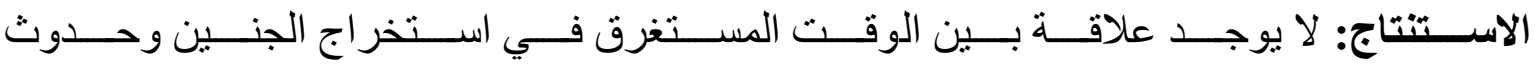
سر عة مؤقتة في معدل تنفس الطفل بعد الو لادة. 